\title{
АНАЛИЗ ИЗМЕНЕНИЙ В ПРАВИЛАХ ИНКОТЕРМС 2020 И ИХ ПРИМЕНЕНИЕ В МЕЖДУНАРОДНОМ КОНТРАКТЕ КУПЛИ-ПРОДАЖИ ТОВАРОВ 2021
}

Алексеева Л.В. магистрант

Научный руководитель: Черноков А.Э. кандидат юридических наук, доцент кафедры гражданского и международного частного права Ленинградский государственный университет им. А.С. Пушкина

Аннотация: В данной статье рассматриваются толкования международных торговых терминов Инкотермс в редакции 2020 года. Проводится группировка терминов по различным основаниям: по обязанностям заключать договор перевозки груза, договор страхования; по моменту перехода риска случайной гибели товара и др. В основе работы лежит отечественный анализ по существу терминов Инкотермс 2020 и практике их применения во внешнеэкономической деятельности. В статье выявляются результаты оценки влияния изменений толкования международных правил «Инкотермс» на развитие международной торговли, что предполагает увеличение объемов поставок по международным контрактам купли-продажи различных товаров. Выявлены изменения трактовок терминов, которые призваны обеспечить более точное понимание в определении места доставки товара и распределении расходов на доставку, что в свою очередь, более точно объясняет, какой контрагент, продавец или покупатель, несет ответственность за выполнение таможенного оформления, беря на себя все возможные риски и расходы. Международные правила «Инкотермс» являются основным документом, который регламентирует условия поставки товара. Правила облегчили процесс ведения торговли, что влечет за собой тенденцию по увеличению мирового товарооборота. Статья представляет собой актуальную информацию для контрагентов по контракту, а также третьих лиц (перевозчиков, страховых организаций, банков, таможни, брокеров), а также для юристов.

Ключевые слова: ИНКОТЕРМС 2020, международный контракт куплипродажи товаров, торговые обычаи, торговые правила, обязанности сторон контракта, права сторон контракта, применимое право, национальное право, 
международное право, контракт международной купли-продажи товаров, договор перевозки, страхование, риск случайной гибели имущества, правила ICC по использованию национальных и международных торговых терминов, условия доставки, изменения в Инкотермс.

\title{
ANALYSIS OF CHANGES IN THE RULES OF INCOTERMS 2020 AND THEIR APPLICATION IN THE INTERNATIONAL CONTRACT FOR PURCHASE AND SALE OF GOODS 2021
}

Alekseeva L.V. Chernokov A.E.

\begin{abstract}
This article discusses the interpretations of Incoterms international trade terms as revised in 2020. Terms are grouped according to various grounds: obligations to conclude a contract for the carriage of goods, an insurance contract; at the moment of transition of risk of accidental loss of goods, etc. The work is based on a domestic analysis of the essence of Incoterms 2020 terms and the practice of their application in foreign economic activity. The article reveals the results of the assessment of the impact of changes in the interpretation of Incoterms international rules on the development of international trade, which implies an increase in the volume of supplies under international contracts for the sale of various goods. Changes in the interpretation of terms were identified, which are designed to provide a more accurate understanding in determining the place of delivery of the goods and distributing the costs of delivery, which in turn explains more precisely which counterparty, seller or buyer, is responsible for carrying out customs clearance, assuming all possible risks and expenses. Incoterms International Rules are the main document that regulates the conditions for the delivery of goods. The rules facilitated the process of trade, which entails a tendency to increase world trade. The article is up-to-date information for counterparties under the contract, as well as third parties (carriers, insurance organizations, banks, customs, brokers), as well as for lawyers.

Key words: INCOTERMS 2020, international contact of goods sale and purchase, trade customs, trade rules, obligations of the parties to the contract, rights of the parties by the contract, applicable law, national law, international law, contract of international sale of goods, contract of carriage, insurance, risk of accidental loss
\end{abstract}




\section{МОДЕРНИЗАЦИЯ СОВРЕМЕННОЙ НАУКИ И ОБРАЗОВАНИЯ: АНАЛИЗ ОПЫТА И ТЕНДЕНЦИЙ}

of property, ICC rules for the use of national and international trade terms, terms of delivery, changes of Incoterms.

Цель правил Инкотермс избежать различной интерпретации самих ее терминов. Как правило, коммерсанты, которые заключают контракт не знакомы с различной практикой ведения торговли в разных странах. Это приводит к различным разногласиям и даже судебным конфликтам. Для решения этих многочисленных проблем Международная торговая палата и разработала в 1936 первый свод правил для точного определения торговых терминов. Позднее выходили новые версии, которые приводили эти правила в соответствие с современной практикой международной торговли.

Самое главное преимущество Инкотермс: сторонам контракта не нужно прописывать полный перечень их прав и обязанностей, если сделана ссылка на условие Инкотермс. На сегодняшний день актуальной версией правил международной торговли является версия Инкотермс 2020. Однако необходимо отметить, что участники внешнеэкономической деятельности имеют право пользоваться версиями и других версий Инкотермс, при этом при ссылке на Инкотермс в контракте обязательно следует указать год используемой версии правил.

Перед заключением контракта купли-продажи товаров, стороны определяют условие работы к конкретной сделке. Правила Инкотермс полностью не могут заменить условия контракта. Они лишь поясняют действия сторон транспортировке товара по сделке, на основе которой заключается контракт. Однако, при несовпадении условий контракта и указанной версии Инкотермс, приоритет отдается условиям контракта. Такие обстоятельства наступают лишь при некомпетентности лица, который составляет текст контракта. В современных международных компаниях в штате отсутствует юрист - международник, к сожалению, так как таких специалистов не так много, их труд стоит дорого и они, как правило, работают в юридических конторах, услугами которых современные бизнесмены среднего бизнеса не пользуются, надеясь на успешную деятельности своего менеджера по ВЭД. Надо отметить, что при несовпадении условий, положений контракта приоритет отдается условиям контракта.

Версии правил Инкотермс меняются в соответствии с современными коммерческими условиями и тенденциями развития мирового товарооборота. 
С принятием новой версии, они все более усовершенствуются, часто они применяются неправильно.

Необходимо отметить, что правила Инкотермс помогают оптимизировать текст контракта международной купли-продажи товаров, а именно не перегружать его лишней детальной информацией о правах и обязанностях сторон, так как их стандартный комплекс уже содержится в самом термине и все участники внешнеэкономической сделки (контрагенты по контракту, а также третьи лица: перевозчики, банки сторон, брокеры, таможенные терминалы и тд.) уже понимают исполнение этих обязанностей.

Как считает Новаков А.А.: «Инкотермс - это очень удобный и практичный внешнеторговый инструмент, позволяющий значительно упростить техническую часть контрактной работы, но каждым инструментом нужно уметь грамотно пользоваться».

Каждый термин, который используется в международных правилах Инкотермс, - это аббревиатура трех букв, где первая указывает на переход обязательств от продавца к покупателю:

- «Е» - с места отправки товара;

- $\quad$ $\mathrm{F} »-$ с терминала отправления товара;

- «C» - с терминала прибытия товара;

- «D»- у покупателя.

Обсуждение сторонами контракта транспортных условий при заключении договора купли-продажи товаров предусматривает изучение алгоритма перевозки грузов, установления перечня документов, необходимых для сопровождения договора перевозки, деталей по срокам отгрузки и доставки, определения стоимости и вида перевозки, а также порядка расчетов по транспортным услугам. Правила «Инкотермс» фиксируют момента перехода рисков по исполнению условий поставки, а также момента перехода права собственности на импортный или экспортный товар по международному контракту купли-продажи.

Современная внешнеэкономическая деятельность требует от участников международных отношений определенных знаний, компетенций и практического опыта данной деятельности. Контрагенты должны знать свои потребности и оценивать свои возможности, а также иметь навыки применения правовых норм и обычаев осуществляя действия в процессе коммерческой 


\section{МОДЕРНИЗАЦИЯ СОВРЕМЕННОЙ НАУКИ И ОБРАЗОВАНИЯ: АНАЛИЗ ОПЫТА И ТЕНДЕНЦИЙ}

деятельности, которые основываются на сложившейся практике и не допускают иных толкований обязательств.

Согласно международному контракту купли-продажи товаров, все участники внешнеэкономической деятельности (контрагенты, таможенные органы участников деятельности, экспедиторы, перевозчики, брокеры, страховые организации, банки сторон) должны быть убеждены в правильности и однозначности понимания прав и своих обязанностей, страхованию, таможенному оформлению, оплате налогов, пошлин и сборов, а также распределению соответствующих рисков. При этом, правила «Инкотермс» позволяют избежать множественности трактовок принимаемых сторонами обязательств в процессе поставки товаров. Международная торговая палата разрабатывает эти правила на основе сложившейся международной коммерческой практики, уточняя и редактируя толкования норм «Инкотермс» согласно всем современным рыночным тенденциям и спорным вопросам.

Внешнеэкономическая деятельность Российской Федерации составляет важную часть ее экономики и эта деятельность невозможна без составления внешнеторговых контрактов и правильного понимания условий поставки.

Одним из основных документов, который регулирует правила, по осуществления внешнеторговой деятельности государств, является Конвенция ООН о договорах международной купли-продажи товаров, принятая в Вене в 1980 году.

Она применяется к вышеупомянутому виду договоров между сторонами, которые находятся в разных государствах, являющихся государствами, заключающими данный договор, или в том случае, когда может применяться право договаривающегося государства. Следует отметить, что данная Конвенция не применима к купле-продаже товаров, которые предназначены для предпринимательского, личного, семейного или домашнего использования.

Контракт международной купли-продажи товаров — это один из видов внешнеэкономической сделки, который заключается сторонами контрагентами коммерческих предприятий, которые находятся на территории различных государств. В качестве источников правового регулирования могут быть международные договоры (конвенции, соглашения), нормы национального законодательства, а также обычаи и правила поставки товаров, как «Инкотермс». 


\section{МОДЕРНИЗАЦИЯ СОВРЕМЕННОЙ НАУКИ И ОБРАЗОВАНИЯ: АНАЛИЗ ОПЫТА И ТЕНДЕНЦИЙ}

Правила Инкотермс ICC по использованию национальных и международных торговых терминов вступили в свою уже девятую, начиная с 1936 года их создания, редакцию. Таким образом, с 1 января 2020 года вступил в силу Инкотермс 2020.

Исследованию последней версии правил Инкотермс 2020, была посвящена статья «Инкотермс 2020: основные изменения для заключения и исполнения» К.В. Холопова, доктора экономических наук, профессора, которая была посвящена особенностям и изменениям Инкотермс 2020.

Главной целью нового издания международных правил Инкотермс 2020 сделать эти правила максимально понятными и удобными для пользования контрагентов внешнеэкономической деятельности. Изменилась структура документа и организация таблиц с обязанностями сторон. Каждое условие поставки проиллюстрировано наглядными схемами.

Некоторые из изменений касаются транспортных обязательств сторон, процедуры исполнения контрактов международной купли-продажи товаров, а также последствий исполнения таких контрактов.

Очень существенным является изменение на довольно распространенное условие поставки - FCA. По данному условию обязательства продавца считаются исполненными в момент передачи товара перевозчику, которого номинирует покупатель. Надо отметить, что при морской перевозке и условии расчетов между сторонами контракта, банки сторон требуют предоставить коносамент с бортовой записью, который выдается после погрузки товара на судно. Согласно новым изменениям, покупатель может дать указание своему перевозчику выдать коносамент с бортовой записью продавцу после погрузки товара, после чего продавец будет обязан предоставить коносамент покупателю, как правило, через банк. На переход рисков это не влияет, и он определяется по общим правилам FCA.

Еще одним существенным изменением является то, что термин DAT заменен на DPU. По новому условию продавец несет ответственность за разгрузку товара в месте назначения. Условие DPU рекомендовано выбирать в том случае, когда продавец знает, все детали о месте выгрузки, иначе лучше выбрать условие DAP (Поставка в месте назначения). Данные условия поставки также являются частотными в их использовании при перевозке сушей.

В новой версии правил усилены требования по условию СРТ (Перевозка оплачена до), а именно то, что транспортный документ должен: 


\section{МОДЕРНИЗАЦИЯ СОВРЕМЕННОЙ НАУКИ И ОБРАЗОВАНИЯ:

1) быть датирован в пределах согласованного периода отгрузки;

2) покрывать весь товар по контракту;

3) предоставлять покупателю возможность потребовать товар от перевозчика в указанном месте назначения и позволить покупателю продать товар в период транзита путем передачи документа последующему покупателю или посредством извещения перевозчика.

Если транспортный документ является оборотным и выдан в нескольких оригиналах, покупателю должен получить полный комплект документов. Если есть ошибки в транспортном документе, продавец должен их исправить, иначе будет просрочка в рамках данного условия поставки.

В новой версии правил Инкотермс 2020:

1) учтены ситуации, когда перевозка товара реализуется собственным транспортом продавца (FCA, DAP, DPU, DDP;

2) все затраты перечислены в статьях А9 / В9 «Распределение расходов» по каждому базису поставки;

3) точно определяется, какая сторона ответственна за таможенное оформление: экспорт, транзит и импорт;

4) вводится обязанность продавца соблюдать требования по безопасности транспорта до пункта назначения, а также предоставлять покупателю эту информацию по необходимости.

Однако, необходимо отметить, что Инкотермс 2020 не заменяют собой контракт купли-продажи товаров, он не устанавливает правовую природу контракта и сам момент перехода права собственности на товар, а также применимое право и ряд других существенных вопросов, которые контрагентам необходимо согласовывать при заключении контракта. В связи с этим, стороны должны детально составлять текста контракта, описывая все спорные моменты, риски сторон и т.д.

Содержание правил Инкотермс 2020 можно разделить на три основные группы по их сферам регулирования:

1) группа, регулирующая обязанности сторон, связанные с надлежащим исполнением обязательства из контракта купли-продажи товаров, а именно по заключению договоров перевозки; страхованию товара; упаковке, проверке и маркировке товара; получению и предоставлению транспортных документов. Чурилов А.Ю. утверждает, что «все эти обязанности не существуют «в отрыве» от норм национального законодательства, и, в случае возникновения 


\section{МОДЕРНИЗАЦИЯ СОВРЕМЕННОЙ НАУКИ И ОБРАЗОВАНИЯ: АНАЛИЗ ОПЫТА И ТЕНДЕНЦИЙ}

обстоятельств, являющихся основанием для освобождения от ответственности одной из сторон, приниматься во внимание будут нормы национального законодательства» [7, С-49].

2) группа, регулирующая порядок поставки и момент перехода рисков. Эта группа правил имеет значение для определения момента исполнения продавцом обязанности по передаче товара покупателю и риски гибели транспортируемого имущества.

3) группа, регулирующая распределение расходов по упаковке, перевозке, импортной/экспортной таможенной очистке.

В зависимости от момента исполнения продавцом обязанности по передаче товара и риски гибели имущества переходят на покупателя, все термины разделяются также на три основные группы:

1) с момента предоставления товара в распоряжение покупателя в месте нахождения продавца не погруженным на транспортное средство (термин EXW);

2) с момента передачи товара перевозчику (все термины группы C и F);

3) с момента доставки товара покупателю (термины DAP, DPU и DDP).

В зависимости от необходимости заключения договора перевозки продавцом или покупателем все термины можно разгруппировать:

1) договор перевозки, заключаемый покупателем (EXW, FCA, FAS, FOB);

2) оговор перевозки, заключаемый продавцом за его счет (CPT, CIP, DAP, DPU, DDP, CFR, CIF).

Bсе термины Инкотермс обязуют покупателя и продавца застраховать товар. По этому принципу все термины разделяются на две группы: CIP);

1) предусматривающие обязанность страховать товар (термины CIF и

2) не предусматривающие обязанность страховать товар - в эту группу входят все остальные термины.

По обязанностям в отношении экспортной/импортной таможенной очистки все термины Инкотермс разделяются на три группы:

1) обязанности как по экспортной, так и по импортной таможенной очистке лежат на покупателе по единственному термину EXW;

2) обязанности как по экспортной, так и по импортной очистке лежат на продавце по единственному термину DDP; 


\section{МОДЕРНИЗАЦИЯ СОВРЕМЕННОЙ НАУКИ И ОБРАЗОВАНИЯ: АНАЛИЗ ОПЫТА И ТЕНДЕНЦИЙ}

3) обязанности по экспортной очистке лежат на продавце, обязанности по импортной очистке - на покупателе. В эту группу входят остальные 9 терминов.

Обязанности и порядок несения расходов термины Инкотермс 2020 закрепляют в одном пункте, что делает более удобным его применение. Общее правило состоит в том, что все расходы несет продавец до момента, когда он считается исполнившим обязанность по передаче товара, и покупатель после момента исполнения этой обязанности. Сторона, которая обязана оказать содействие, имеет право на возмещение расходов, которые она понесла, в связи с этим содействием. Помимо этого, покупатель обязан оплатить любые дополнительно возникшие расходы, связанные с неисполнением обязанности по направлению извещений продавцу, неприбытия транспорта в установленный срок и тому подобные обстоятельства.

Все вышеперечисленные обстоятельства и обязанности сторон, лучше всего, помимо простого указания термина в контракте, прописывать в соответствующих пунктах контракта.

При обсуждении сторонами контракта транспортных условий предусматривает изучение алгоритма перевозки грузов, установления перечня необходимых документов, необходимых для сопровождения договора перевозки и требования к их оформлению, а также детализации сроков отгрузки и доставки, в том числе и определения стоимости перевозки и порядка расчетов, связанных с транспортировкой груза.

Чурилов А.Ю., анализируя условия, значения и, в том числе, их правовую основу, по FOB и CIF условиям Инкотермс 2020 утверждает, что «несмотря на существование универсальных правил толкования торговых терминов ИНКОТЕРМС, стороны вправе изменять условия договора в той степени, в которой эти изменения будут соответствовать существу применяемого торгового термина» [8, C-48].

Необходимо отметить, что целью правил «Инкотермс» является выработка комплекса правил толкования торговых терминов, используемых во внешней торговле и данный свод правил рассматривается как правой акт. К примеру, Пахаруков А.А. рассматривает в своей статье «Инкотермс как правовой акт» юридическое значение «Инкотермс» и характеризует его как правовой акт. «Инкотермс может рассматриваться как акт индивидуального правового регулирования, выполняющего регулирующую функцию, как акт 


\section{МОДЕРНИЗАЦИЯ СОВРЕМЕННОЙ НАУКИ И ОБРАЗОВАНИЯ: АНАЛИЗ ОПЫТА И ТЕНДЕНЦИЙ}

профессионального толкования, целью которого является разъяснения содержания торговых терминов, как гармонизационный акт, фиксирующий обычные нормы и обеспечивающий процесс сближения права разных государств» [5, C-313].

Необходимо отметить, что термины Инкотермс не заменяют собой правовую систему, но действуют в ее рамках. Те вопросы, которые остаются неурегулированными, - разрешаются в соответствии с нормами национального или выбранного применимого права по контракту.

В связи с этим, большое значение для юристов-международников, которые занимаются внешнеэкономической торговой деятельностью, данная обновленная редакция «Инкотермс» 2020 также представляет большое значение для составления корректной взаимосвязи всех пунктов по контракту купли-продажи товаров и обязательной коррекции в тексте контракта ссылки на уже действующую редакцию «Инкотермс» 2020.

Современный рынок транспортных услуг требует от участников международных отношений серьезных знаний и компетенции в этой области для принятия правильных решений по определению нужного условия поставки товара по внешнеэкономическому контракту. Контрагенты должны определить свои потребности, возможности, а также иметь навыки применения правовых норм и обычаев осуществляя необходимые действия в процессе предпринимательской деятельности, основываясь на сложившейся практике.

Резюмируя вышесказанное, можно сделать вывод, что по контракту купли-продажи товаров участники международной торговли должны быть уверены в правильности и однозначности понимания прав и обязанностей сторон по транспортировке, страхованию, таможенному оформлению, оплате налогов, пошлин и сборов, а также распределению рисков между сторонами. В этой связи стандартные правила «Инкотермс» позволяют избежать множественности трактовок принимаемых сторонами обязательств в процессе поставки различных товаров.

Внимание к проблеме условий поставок в современной коммерции усиливается и связано это, в первую очередь с разработкой единообразного, однозначного и достоверного толкования обязательств сторон для полного их понимания всеми участниками международных сделок, как контрагентами по контракту, так и третьими сторонами, вовлеченными во внешнеэкономическую деятельность по контракту (перевозчики груза, банки, страховые организации, брокеры). 
Одновременно с перечисленным выше, все термины содержат правила о содействии сторон при осуществлении импортной и экспортной очистки. Это требование является прямым проявлением такого принципа гражданского права как принцип содействия сторон, которое выражается в предоставлении сторонами друг другу необходимой для обязательства информации.

Обязанности и порядок несения расходов термины Инкотермс в обновленной версии 2020 закрепляют в одном пункте, что сделало более удобным его применение. Общее правило состоит в том, что все расходы несет продавец до момента, когда он считается исполнившим обязанность по передаче товара, а покупатель после момента исполнения этой обязанности. Необходимо отметить, что сторона, которая обязана оказать содействие, имеет право на возмещение расходов, которые она понесла, в связи с этим содействием.

Кроме того, покупатель обязан оплатить любые дополнительные расходы, связанные с неисполнением обязанности по направлению извещений продавцу, неприбытия транспорта в установленный срок, что является существенным и актуальным в современной коммерции.

Периодически решая задачи современной актуализации правил «Инкотермс», достигается цель предельного упрощения и, даже, отказа от базисов поставок, вызывающих неоднозначную интерпретацию обязательств при использовании условий, связанных с поставкой товара.

В правилах «Инкотермс» 2020 произошли кардинальные изменения в части отказа от дальнейшего применения терминов EXW, FAS и DDP, а также предложены более приемлемые и удобные для понимания сторонами контракта условия по данным международным правилам.

Изменения в «Инкотермс» 2020 года преследуют лишь одну цель адаптировать базисные условия поставки под реалии современного мира, облегчить осуществление внешнеторговых операций, что является стимулом для увеличения мирового товарооборота. 


\section{Список литературы}

1. Конвенция Организации Объединенных Наций о договорах международной купли-продажи товаров (Заключена в г. Вене 11.04.1980)/ [Электронный источник] / http://www.consultant.ru/document/cons_doc_LAW_ 2648 / (дата обращения 02.05.2021).

2. Incoterms 2020 / [Электронный источник] / https://2go.iccwbo.org/ incoterms-2020-app / (дата обращения 01.05.2021).

3. Бурханов С.Б., Вальков В.Е. Анализ изменений толкования правил «Инкотермс» 2020 и их использование в развитии морских перевозок // Научные труды Дальрыбвтуза. 2020. Т. 53, № 3. С. 96-108.

4. Леонова О.В. Внешнеторговый контракт с изменениями 2020 г. // Российский внешнеэкономический вестник. 2020. № 7. С. 47-57.

5. Пахаруков А.А. Инкотермс как правовой акт // Социальная компетентность. 2020. Том 5. № 3 (17). С. 303-315.

6. Холопов К.В. Инкотермс 2020: основные изменения для заключения и исполнения договоров международной купли-продажи товаров // Российский внешнеэкономический вестник. 2020. № 1. С. 7-16.

7. Чурилов А.Ю. Особенности использования Инкотермс 2020 в международной коммерческой практике // Российский внешнеэкономический вестник. 2020. № 7. С. 47-57.

8. Чурилов А.Ю. Классификация СIF и FОВ договоров и ее значение // Российский внешнеэкономический вестник. 2021. № 1. С. 44-50.

9. Новаков А.А. Логистика в деталях: учебное пособие: [12+] / А.А. Новаков. - Москва; Вологда: Инфра-Инженерия, 2021. - 528 с. 